\title{
Molecular characterization of methicillin-resistant Staphylococcus aureus among insulin-dependent diabetic individuals in Brazil
}

\author{
Nathalia Bibiana Teixeira ${ }^{1,2,4^{*}}$ (0, Carlos Magno Castelo Branco Fortaleza ${ }^{1}$, Matheus Cristovam de Souza ${ }^{2}$, \\ Thais Aline Monteiro Pereira², Bibiana Prada de Camargo Colenci ${ }^{3}$ and \\ Maria de Lourdes Ribeiro de Souza da Cunha²
}

\begin{abstract}
Background: People with diabetes mellitus, especially insulin-dependent diabetic patients, are a risk group for staphylococcal infections. Asymptomatic infection with Staphylococcus aureus is common and favors dissemination of the microorganism, rendering these individuals a source of infection. This study aimed to characterize the resistance profile, clonal profile and sequence type, as well as to analyze the prevalence and risk factors for nasal and oropharyngeal carriage of methicillin-susceptible (MSSA) and methicillin-resistant S. aureus (MRSA) isolated from insulin-dependent diabetic individuals in the city of Botucatu, SP, Brazil.

Methods: Staphylococcus aureus was collected from the nasopharynx and oropharynx of 312 community-dwelling insulin-dependent diabetic individuals over a period of 3 years (October 2015 to December 2018). The isolates were characterized by susceptibility profiling, detection of the mecA gene, SCCmec typing, and molecular typing by PFGE and MLST. The risk factors associated with S. aureus and MRSA carriage were determined by logistic regression analysis.

Results: The overall prevalence of colonization with S. aureus and MRSA was $30.4 \%$ and $4.8 \%$, respectively. Fifteen of the 112 S. aureus isolates carried the mecA gene; SCCmec type IV was identified in 10 isolates, SCCmec type I in three, and SCCmec type II in two. Among the 15 resistant isolates (MRSA), four were susceptible to oxacillin/cefoxitin by the disc diffusion method and one MSSA isolate was resistant to sulfamethoxazole/trimethoprim. The analysis of risk factors revealed a protective effect of age and lung disease, while lower-extremity ulcers were a risk factor for $S$. aureus. For MRSA, only male gender was significantly associated as a risk factor in multivariate analysis. Clonal profile analysis demonstrated the formation of clusters among MRSA isolates from different patients, with the identification of ST5-IV, ST5-I, and ST8-IV. Isolates carrying ST398 were identified among MSSA and MRSA (ST398-IV).
\end{abstract}

Conclusion: Our findings reinforce the importance of epidemiological studies of $S$. aureus carriage, especially in populations at high risk of infections such as diabetics. The data suggest widespread dissemination of MRSA in the

\footnotetext{
*Correspondence: na_tx0402@yahoo.com.br

${ }^{4}$ Departamento de Ciências Químicas e Biológicas - Setor Microbiologia e Imunologia, Instituto de Biociências de Botucatu (IBB)-Laboratório de Bacteriologia. Rua Plínio Silva, CEP: 18618-970 - Distrito de Rubião Júnior, Botucatu, SP, Brasil

Full list of author information is available at the end of the article
}

(c) The Author(s) 2021. This article is licensed under a Creative Commons Attribution 4.0 International License, which permits use, sharing, adaptation, distribution and reproduction in any medium or format, as long as you give appropriate credit to the original author(s) and the source, provide a link to the Creative Commons licence, and indicate if changes were made. The images or other third party material in this article are included in the article's Creative Commons licence, unless indicated otherwise in a credit line to the material. If material is not included in the article's Creative Commons licence and your intended use is not permitted by statutory regulation or exceeds the permitted use, you will need to obtain permission directly from the copyright holder. To view a copy of this licence, visit http://creativeco mmons.org/licenses/by/4.0/. The Creative Commons Public Domain Dedication waiver (http://creativecommons.org/publicdomain/ zero/1.0/) applies to the data made available in this article, unless otherwise stated in a credit line to the data. 
population of insulin-dependent diabetic patients studied, as well as the emergence of important lineages among these individuals.

Keywords: Methicillin-resistant Staphylococcus aureus (MRSA), Diabetes mellitus, Insulin, Resistance, Nasal or oropharyngeal carriage, Molecular typing

\section{Background}

Diabetes mellitus is a progressive chronic disease characterized by high blood glucose levels, which is one of the most prevalent diseases in modern societies. Its treatment is often inadequate or absent [1]. It is estimated that more than 370 million people worldwide have diabetes and more than 5 million deaths were attributed to the disease and its complications in 2017 [2, 3].

People with diabetes are known to be more susceptible to infections because of their elevated blood glucose levels and suppression of the immune response. In addition, neuropathy and reduced blood flow to the extremities are common in these individuals. Consequently, wounds tend to heal more slowly, increasing the risk of amputations and death $[4,5]$.

Staphylococcus aureus is one of the leading causes of infections in diabetic individuals. This microorganism plays a particularly important role in this scenario by causing infections that range from superficial to severe and potentially fatal systemic infections, in addition to its ability to acquire resistance to multiple drugs. In the past, the pathogen was mainly found in hospital settings; however, we are now witnessing an increase particularly of resistant isolates (MRSA) acquired in the community that are genetically different from traditional nosocomial strains [6-8]. Infections caused by methicillin-resistant S. aureus (MRSA) are associated with a higher mortality rate compared to infections caused by methicillinsusceptible S. aureus (MSSA) [2]. Furthermore, studies suggest that staphylococcal infections are preceded by colonization with these microorganisms $[2,9-13]$ and at least one third of colonized healthy adults are at risk of developing subsequent invasive infections $[6,7]$.

Bacterial resistance has become a major global threat. In the study of Onanuga and Temedie [14], the prevalence of multidrug-resistant MRSA isolated from the anterior nares of diabetic patients was $52.5 \%$. This prevalence was $40 \%$ among diabetic outpatients in the study of Kutlu et al. [15]. High antimicrobial resistance of MRSA isolated from diabetic patients has also been reported by Alizargar et al. [16], with rates of erythromycin, ciprofloxacin and clarithromycin resistance of $81.9 \%, 71.3 \%$ and $65.5 \%$, respectively, and a multidrug resistance rate of 59\%. Two vancomycin-resistant Staphylococcus aureus strains were isolated in that study [16].
Diabetic individuals are considered a risk group for skin infections such as those caused by $S$. aureus and are also more prone to developing severe systemic infections [13]. Studies have shown that the prevalence of nasal colonization with S. aureus (27-56.6\%) and MRSA (1-7.3\%) varies according to geographic location and that the use of insulin is a risk factor for nasal MRSA carriage in diabetic individuals [16]. However, little is known about the role of throat colonization in this population.

Staphylococcus aureus is characterized by a high adaptation potential demonstrated by its success in surviving in different environments and the constant emergence of new lineages that cause different clinical manifestations and exhibit rapid epidemiological dissemination, causing a significant impact on health [17]. Globally disseminated MRSA clones included healthcare-associated [HA]-MRSA. The prevalence of this microorganism has also been increasing among community-associated [CA]MRSA and livestock-associated [LA]-MRSA infections [17]. However, studies have demonstrated an exchange of these lineages with CA-MRSA, causing outbreaks of healthcare-associated infections in the community, and HA-MRSA being isolated in community settings $[18,19]$. LA-MRSA have also been reported in individuals without any previous contact with animals [17].

Staphylococcal cassette chromosome (SCCmec) typing is a useful epidemiological tool since different types are more prevalent in hospital or community settings. Unlike HA-MRSA that harbor large SCCmec (SCCmec types I, II and III) and are frequently multidrug-resistant, CA-MRSA are associated with SCCmec types IV and $\mathrm{V}$, which are smaller and only carry the mecA gene of methicillin resistance [20-23].

In view of their complex epidemiology, S. aureus and MRSA lineages have been identified by techniques such as pulsed-field gel electrophoresis (PFGE), an adequate tool for the study of local outbreaks. Studies investigating the clonality of $S$. aureus are frequently complemented by multilocus sequence typing (MLST), which permits comparisons between $S$. aureus sequences described in different parts of the world. MLST and SCCmec typing have been used for the identification of global MRSA clones, which resulted in the detection of five large MRSA clonal complexes (CC) including CC5, CC8, CC $30, \mathrm{CC} 45$, and CC398 $[24,25]$. 
Considering their impact on the health of diabetic individuals, a better understanding of the epidemiology of and risk factors for colonization with $S$. aureus and MRSA is necessary. The aim of this study was to characterize the resistance profile, clonal profile and sequence type, as well as to analyze the prevalence and risk factors for nasal and oropharyngeal carriage of MSSA and MRSA isolated from insulin-dependent diabetic individuals in the city of Botucatu, SP, Brazil.

\section{Materials and methods Study design}

This was a cross-sectional study conducted in the city of Botucatu, São Paulo, Brazil, whose estimated population is 146,497 inhabitants [26]. We calculated the sample size from a population of 1631 individuals using an expected proportion of $50 \%$ (the typical value used in situations in which the proportion is unknown), considering a power of $80 \%$ (i.e., a beta error of $20 \%$ ) and an alpha error of $5 \%$, with a design effect of 1.0 (since no subsampling was performed). The formula used for sample size calculation is given in Additional file 1: Appendix S1. Using this calculation for proportions, we obtained a suggested $n$ of 312 subjects. The subjects were selected randomly from the database of the Municipal Health Department over a period of 3 years (October 2015 to December 2018). If possible, the subjects were recruited during home visits $(n=204)$; however, in view of the difficulty in locating these individuals at the addresses obtained, many of them were invited by telephone to the events promoted at Basic Health Units $(\mathrm{n}=70)$. Some subjects were recruited at the doctor's offices $(n=23)$ and at the headquarter of the Botucatu Association for Diabetes Support (ABAD in the Portuguese acronym) $(n=15)$. A questionnaire including the following data was applied to subjects who agreed to participate in the study: demographic data (gender and age); type of diabetes (1 or 2 ); time since diagnosis (years); time of insulin use (years); clinical data (comorbidities); presence of ulcers or amputations; tattoos; hospitalizations or medical procedures in the last year; and use of antimicrobials in the last year. All data were obtained by interview with the patient and/or legal representative following ethical standards. The questionnaires were extensively reviewed for inconsistencies.

\section{Inclusion and exclusion criteria}

All insulin-dependent diabetic patients living in the city of Botucatu, who agreed to participate by signing the free informed consent form (Additional file 1: Table S1), were included in the study. Patients who did not consent to participate in the study, patients who did not use insulin at the time of data collection, patients who had died, and patients who could not be found based on their personal data were excluded (Additional file 1: Table S2).

\section{Collection of microbiological specimens}

Nasal and oral mucosa samples were collected from 312 insulin-dependent diabetic individuals living in the city of Botucatu, São Paulo, Brazil, using sterile swabs in transport medium. Samples from the anterior nares and oropharynx were obtained using one swab for each site. For the collection of nasal samples, the swab was immersed in $0.9 \%$ sterile saline and inserted into both nares, rotating it and gently pressing its end against the mucosa. The technique for oropharyngeal sampling consisted of immersion of the swab and passing it gently over the surface of the throat, avoiding contact of the examiner with the tongue.

The swabs were transported in Stuart medium to the Laboratory of Bacteriology, Department of Microbiology and Immunology, Institute of Biosciences, UNESP, and seeded onto plates containing Baird-Parker agar, a selective medium for Staphylococcus. After incubation for $48 \mathrm{~h}$ at $37^{\circ} \mathrm{C}$, the isolated microorganisms were identified.

\section{Identification of Staphylococcus aureus}

The microorganisms were submitted to Gram staining for observation of their morphology and specific staining. After confirmation of these features, catalase and coagulase tube tests and biochemical tests (maltose, trehalose, and mannitol) were carried out to differentiate $S$. aureus from other Staphylococcus species [27, 28].

After DNA extraction with the Illustra Kit (GE Healthcare, Little Chalfont, Buckinghamshire, UK), the $S$. aureus isolates were confirmed genotypically by detection of the 16S rRNA gene [29] and the DNA SA442 fragment specific for S. aureus [30]. Thus, 112 S. aureus isolated obtained from 312 patients included in the study were identified.

\section{Antimicrobial susceptibility testing}

All 112 isolates obtained were subjected to antimicrobial susceptibility testing by the disc diffusion method using impregnated discs according to the criteria of the Clinical Laboratory Standards Institute (CLSI) [31]. The inoculum was adjusted to a $0.5 \mathrm{McFarland}$ standard and seeded onto Mueller-Hinton agar and the plates were incubated for $24 \mathrm{~h}$ at $35{ }^{\circ} \mathrm{C}$. The following drugs were used: oxacillin $(1 \mu \mathrm{g})$, cefoxitin $(30 \mu \mathrm{g})$, linezolid $(30 \mu \mathrm{g})$, quinupristin/dalfopristin $(15 \mu \mathrm{g})$, and sulfamethoxazole/trimethoprim $(25 \mu \mathrm{g})$. Antimicrobial activity was evaluated by determining the diameter of the inhibition zone, which was interpreted according to the CLSI [31]. 
International reference strains were used as controls for MSSA (S. aureus ATCC 25923) and MRSA (S. aureus ATCC 33591).

\section{Determination of the minimum inhibitory concentration} The minimum inhibitory concentration (MIC) of vancomycin was determined by the E-test in all $112 \mathrm{~S}$. aureus isolates. This quantitative test uses inert and transparent plastic strips ( $60 \mathrm{~mm}$ long $\times 5.5 \mathrm{~mm}$ wide) with a predefined gradient of concentrations of the antimicrobial to be tested. The MIC results were classified as susceptible, intermediate, or resistant according to the definitions of the CLSI [31]. An international reference strain (S. aureus ATCC 29213) was included as control.

\section{Detection of the mecA gene of methicillin resistance}

All $S$. aureus isolates were analyzed regarding the presence of the mecA gene by PCR following the parameters described by Murakami et al. [32]. International reference strains were included as positive (S. aureus ATCC 33591) and negative (S. aureus ATCC 25923) controls in all reactions. All isolates in which the mecA gene was detected were classified as MRSA, regardless of the result of the oxacillin and cefoxitin disc diffusion tests.

\section{Determination of staphylococcal cassette chromosome mec (SCCmec) type}

SCCmec typing was performed by multiplex PCR as described by Oliveira and de Lencastre [33] and updated by Milheiriço et al. [34] on all mecA gene-positive $S$. aureus isolates. The following strains were used as controls: COL for SCCmec type I; N315 for SCCmec type IA; PER34 for SCCmec type II; AN546 for SCCmec type III; HU25 for SCCmec type IIIA, and MW2 for SCCmec type IV.

\section{Visualization of amplified products}

The efficiency of the amplifications was confirmed by electrophoresis on $2 \%$ agarose gel prepared in $0.5 \mathrm{M}$ Tris-borate-EDTA (TBE) buffer. A 100-bp marker was used as molecular weight standard. The gel was stained with $\mathrm{SYBR}^{\circledR}$ Safe and photographed under UV transillumination.

\section{Pulsed field gel electrophoresis (PFGE)}

The modified protocol of McDougal et al. [35] was used to type all $112 \mathrm{~S}$. aureus isolates by PFGE. The isolates were grown in BHI broth for $24 \mathrm{~h}$. Next, $400 \mu \mathrm{L}$ of the sample was added to a microtube and centrifuged at $12,000 \mathrm{rpm}$ for $50 \mathrm{~s}$. The supernatant was discarded and $300 \mu \mathrm{L}$ TE solution (10 mM Tris, $1 \mathrm{mM}$ EDTA, $\mathrm{pH}$ 8.0) was added. The samples were kept in a water bath for $10 \mathrm{~min}$ at $37^{\circ} \mathrm{C}$. After vortexing, $5 \mu \mathrm{L}$ lysostaphin $(1 \mathrm{mg} /$
$\mathrm{mL}$ in $20 \mathrm{mM}$ sodium acetate, $\mathrm{pH} 4.5)$ and $300 \mu \mathrm{L}$ lowmelting agarose were added.

The samples were transferred to plug molds. The plugs were allowed to solidify and then placed in a 24-well plate with $2 \mathrm{~mL}$ EC solution $(6 \mathrm{mM}$ Tris- $\mathrm{HCl}, 1 \mathrm{M} \mathrm{NaCl}$, $100 \mathrm{mM}$ EDTA, 0.5\% Brij-58, 0.2\% sodium deoxycholate, $0.5 \%$ sodium lauroyl sarcosine) and incubated at $37^{\circ} \mathrm{C}$ for at least $4 \mathrm{~h}$. The EC solution was removed and the plugs were washed four times with $2 \mathrm{~mL}$ TE at room temperature at intervals of $30 \mathrm{~min}$.

The SmaI enzyme (Fast Digest SmaI, Life Science, Canada) was used for restriction of genomic DNA. Electrophoresis was carried out in a CHEF-DR III System (BioRad Laboratories, USA) on 1\% agarose gel prepared with $0.5 \mathrm{M}$ TBE (Pulsed Field Certified Agarose, BioRad Laboratories, USA) under the following conditions: pulse switch time of 5 to $40 \mathrm{~s}$ for $21 \mathrm{~h}$ using a linear ramp; $6 \mathrm{~V} /$ $\mathrm{cm}$; angle of $120^{\circ} ; 14^{\circ} \mathrm{C}$; $0.5 \mathrm{M} \mathrm{TBE}$ as running buffer. The Lambda PFG Ladder (New England BioLabs) was used as molecular marker. The gel was stained with Gel$\operatorname{Red}(10,000 \times$ in water; Biotium, USA) for $1 \mathrm{~h}$ and photographed under UV transillumination.

Similarity was analyzed with the BioNumerics 7.6 software (Applied Maths, Belgium). The dendrogram was constructed by the UPGMA method (Unweighted Pair Group Method with Arithmetic Mean), with band position tolerance and optimization adjusted to $1.2 \%$ and $1 \%$, respectively.

Forty-five isolates, including one MRSA, could not be typed with the SmaI enzyme and were therefore digested with the ApaI restriction enzyme.

A similarity coefficient $\geq 80 \%$ was chosen for the determination of clusters. A cluster was defined as a group of three or more isolates showing $\geq 80 \%$ similarity.

\section{Multilocus sequence typing (MLST)}

Lineages representative of the clusters obtained by PFGE were selected for MLST. Five MRSA isolates obtained PFGE-SmaI and four MSSA isolates obtained by PFGEApaI were chosen.

MLST was performed according to the protocol of Enright et al. [36] by amplification and sequencing of seven housekeeping genes $(\operatorname{arcC}$, aroE, $g l p \mathrm{~F}, g m k, p t a$, $t p i$, and $y q i \mathrm{~L}$ ). The PCR products were purified using the HiYield ${ }^{\mathrm{TM}}$ Gel/PCR Fragments Extraction Kit and the sequencing reactions were performed in an ABI3500 8-capillary sequencer $(50 \mathrm{~cm})$ using POP7 as polymer (Applied Biosystems). The BioNumerics 7.6 program (Applied Maths, Belgium) was used for visualization of the sequences (electropherogram). The sequences were analyzed and compared to an online database (http:// www.mlst.net) (2004). 


\section{Statistical analysis}

The Epi-Info for Windows software (version 7.26; (C)enters for Disease Control and Prevention, Atlanta, USA) was used for univariate analysis. Dichotomous variables were compared using nonparametric tests of proportion, $\mathrm{X}^{2}$ test, and Fisher's exact test. Numerical variables were compared by the Mann-Whitney U test.

Multivariate analysis was performed with the SPSS 20.0 software (@SPSS, Inc.) using a logistic regression model. The outcomes of interest were the overall presence of $S$. aureus or the presence of MRSA irrespective of sampling site. The variables were selected using a backward stepwise strategy. The criterion for entry and permanence of the variables in the models was $\mathrm{p}<0.1$. Final statistical significance was set at $\mathrm{p}<0.05$.

\section{Results}

Prevalence of Staphylococcus aureus and MRSA carriage Ninety-five of the 312 subjects included in the study were colonized with $S$. aureus, corresponding to an overall prevalence of $30.4 \%$ (95\%CI25.6-35.8\%). Fifteen of the 95 subjects were colonized with MRSA either in the nose and/or oropharynx, corresponding to a prevalence of $4.8 \%$ (95\%CI $2.9-7.8 \%$ ). Regarding the sampling site, S. aureus was isolated exclusively from the nose in 44 (14.1\%) individuals, exclusively from the oropharynx in 34 (10.9\%), and from both sites in 17 (5.4\%). Analysis of MRSA demonstrated that eight of the 15 colonized individuals carried the microorganism exclusively in the nose and six exclusively in the oropharynx. Interestingly, one subject carried MSSA in the oral mucosa and MRSA in the nasal mucosa (Fig. 1).

\section{Determination of in vitro antimicrobial susceptibility}

All 112 isolates identified as S. aureus were submitted to in vitro antimicrobial susceptibility testing as previously described. The disc diffusion method revealed 11 strains that were resistant to oxacillin and cefoxitin, including seven resistant to both drugs and four that were resistant only to cefoxitin (inhibition zone $\leq 21$ ). It should be noted that four of the isolates that were susceptible to both drugs exhibited resistance by the genotypic method.

Among all isolates, only one was resistant to sulfamethoxazole/trimethoprim and there was no case of resistance to quinupristin/dalfopristin or linezolid. In addition, the MIC50 and MIC90 for vancomycin were 0.50 and $1.0 \mu \mathrm{g} / \mathrm{mL}$, respectively, and all isolates were susceptible (Supplementary Material Table S3).

\section{Detection of the mecA gene and characterization of SCCmec}

Fifteen of the $112 \mathrm{~S}$. aureus isolates carried the mecA gene of methicillin resistance. There was a predominance of the SCCmec type IV among isolates $(n=10)$, but three isolates harboring SCCmec type I and two harboring SCCmec type II were also identified. Most individuals harboring MRSA isolates reported no contact with the hospital environment in the last year, except for one subject with SCCmec type II and one with SCCmec type IV.

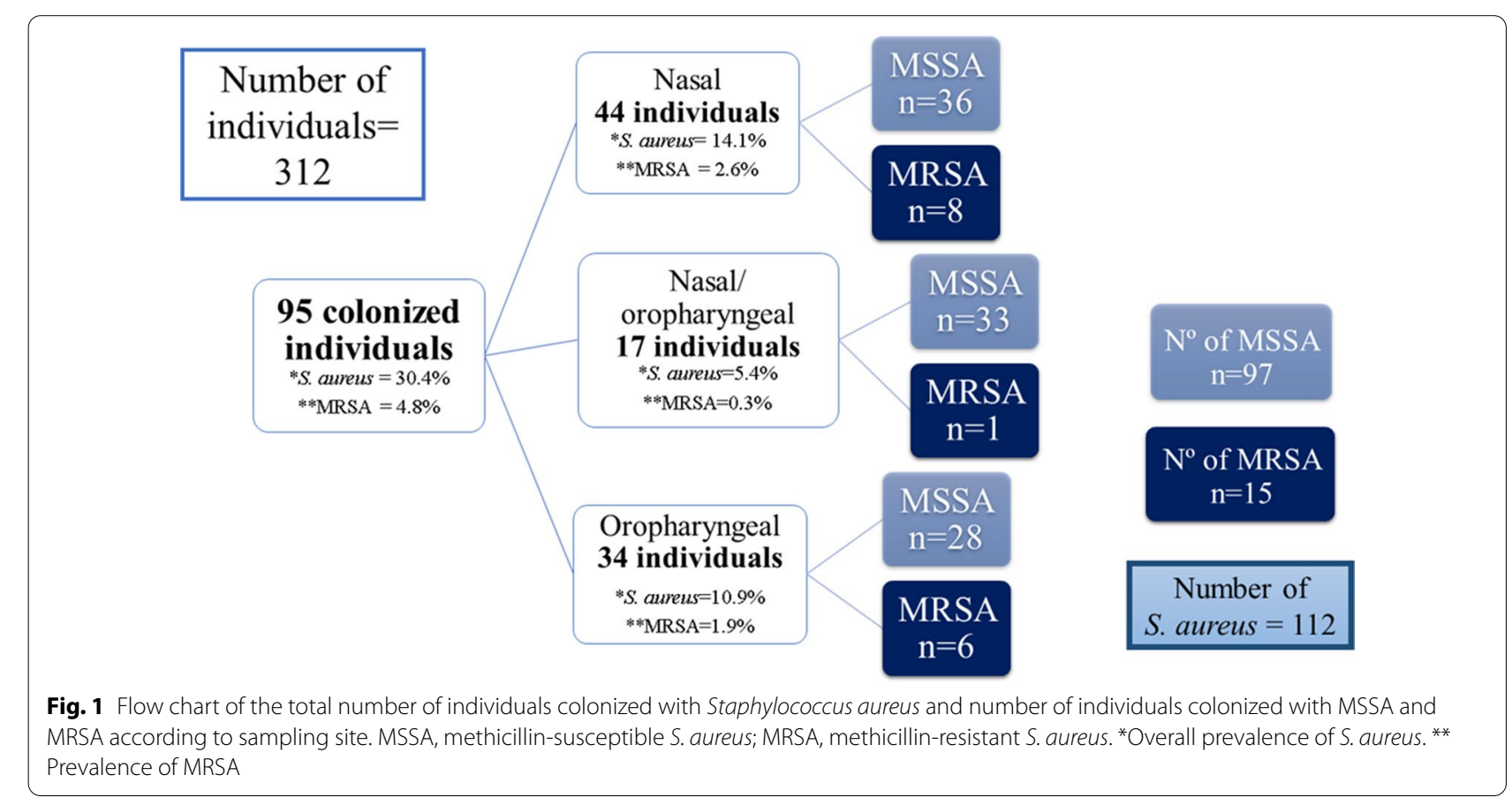


Risk factors for S. aureus and MRSA carriage

All patients in the study used insulin and $78(82.1 \%)$ had type 2 diabetes. A total of 198 (63.4\%) also used other hypoglycemic drugs. The incidence of complications was high: $132(42.3 \%)$ patients had retinopathy and 31 (9.9\%) renal impairment. Thirty-one (9.9\%) patients reported lower-extremity ulcers and 10 of them [3.2\%] had undergone amputation.

The results of univariate and multivariate (logistic regression model) analysis to identify risk factors for $S$. aureus and MRSA carriage are shown in Tables 1 and 2 . With respect to risk factors for $S$. aureus carriage, univariate analysis showed a protective effect (median 61 years, $p=0.04)$, heart disease $(\mathrm{OR}=0.51,95 \% \mathrm{CI} 0.28-0.95$, $p=0.03)$ and lung disease $(\mathrm{OR}=0.28,95 \% \mathrm{CI} 0.10-0.83$, $p=0.02$ ), while only the presence of lower-extremity ulcers was a risk factor $(\mathrm{OR}=2.36,95 \% \mathrm{CI} 1.11-5.01$, $p=0.02)$. However, the only factors that remained independently associated with $S$. aureus carriage in insulindependent diabetic individuals were age $(\mathrm{OR}=0.98,95 \%$ CI $0.93-0.99, p=0.02)$ and lung disease $(\mathrm{OR}=0.31,95 \%$ CI $0.10-0.92, p=0.03)$, which were protective. The only risk factor was leg ulcer $(\mathrm{OR}=2.44,95 \% \mathrm{CI} 1.11-5.34$, $p=0.03)$.
The study of risk factors for MRSA carriage revealed only male gender as a risk factor in uni- and multivariate analysis $(\mathrm{OR}=3.64,95 \% \mathrm{CI} 1.12-11.78, p=0.03)$.

\section{Determination of the clonal profile of $S$. aureus and MRSA by pulsed-field gel electrophoresis (PFGE)}

A total of $112 \mathrm{~S}$. aureus isolates were analyzed by PFGE. Forty-five of these isolates could not be typed repeatedly with SmaI, including one MRSA isolate. However, molecular typing of all 45 isolates was possible using the ApaI enzyme.

For clonal profile analysis, one dendrogram was constructed for susceptible $S$. aureus isolates (MSSA) and one for resistant isolates (MRSA) using SmaI and ApaI, which permitted to identify clusters with similarity $\geq 80 \%$ in both groups.

Figure 2 shows the dendrogram of the PFGE-SmaI and PFGE-ApaI profiles of MRSA isolates, as well as their in vitro susceptibility profile to oxacillin and cefoxitin, presence of the mecA gene, SCCmec type and MLST analysis. Analysis of PFGE-SmaI isolates revealed the presence of two clusters (A and B). Cluster A contained five isolates, four of them showing $100 \%$ similarity $(554 \mathrm{O}$, $555 \mathrm{~N}, 659 \mathrm{~N}$, and $665 \mathrm{~N}$ ). All of them were isolated from

Table 1 Uni- and multivariate (logistic regression) analysis of predictors of Staphylococcus aureus carriage in diabetic individuals

\begin{tabular}{|c|c|c|c|c|c|c|}
\hline \multirow[t]{2}{*}{ Factor } & \multirow[t]{2}{*}{ S. aureus $(n=95)$} & \multirow[t]{2}{*}{ Negative $(n=217)$} & \multicolumn{2}{|c|}{ Univariate analysis } & \multicolumn{2}{|c|}{$\begin{array}{l}\text { Logistic regression } \\
\text { (multivariate) }\end{array}$} \\
\hline & & & OR $(95 \% \mathrm{Cl})$ & $p$ & OR $(95 \% \mathrm{Cl})$ & $p$ \\
\hline Male gender & $42(44.2)$ & $98(45.2)$ & $0.96(0.59-1.56)$ & 0.88 & & \\
\hline Age (median, quartiles) & $61(49-70)$ & $65(56-71)$ & - & 0.04 & $0.98(0.93-0.99)$ & 0.02 \\
\hline Time since diagnosis, years (median, quartiles) & $14(9-20)$ & $16.5(8-25)$ & - & 0.84 & & \\
\hline Use of insulin, years (median, quartiles) & $8(4-14)$ & $7(3-11)$ & - & 0.22 & & \\
\hline Diabetes type 2 & $78(82.1)$ & $184(84.8)$ & $0.82(0.43-1.56)$ & 0.35 & & \\
\hline Heart disease & $16(17.4)$ & $61(29.0)$ & $0.51(0.28-0.95)$ & 0.03 & & \\
\hline Lung disease & $4(4.3)$ & $29(13.8)$ & $0.28(0.10-0.83)$ & 0.02 & $0.31(0.10-0.92)$ & 0.03 \\
\hline Kidney disease & $23(25.0)$ & $59(28.1)$ & $0.85(0.49-1.49)$ & 0.58 & & \\
\hline Liver disease & $9(9.8)$ & $18(8.6)$ & $1.16(0.50-2.68)$ & 0.73 & & \\
\hline CNS disease & $19(20.7)$ & $31(14.8)$ & $1.50(0.80-2.82)$ & 0.20 & & \\
\hline Cancer & $11(11.8)$ & $28(13.1)$ & $0.89(0.42-1.87)$ & 0.75 & & \\
\hline Trauma & $8(8.7)$ & $23(11.0)$ & $0.77(0.33-1.80)$ & 0.55 & & \\
\hline Tattoo & $4(4.3)$ & $12(5.7)$ & $0.75(0.23-2.39)$ & 0.78 & & \\
\hline Lower-extremity ulcers & $15(16.3)$ & $16(7.6)$ & $2.36(1.11-5.01)$ & 0.02 & $2.44(1.11-5.34)$ & 0.03 \\
\hline Amputation & $2(2.2)$ & $8(3.8)$ & $0.56(0.18-2.70)$ & 0.73 & & \\
\hline Charlson comorbidity index $\geq 1$ & $3(2-4)$ & $3(2-4)$ & - & 0.84 & & \\
\hline Hospitalization in the last year & $11(12.0)$ & $37(17.6)$ & $0.63(0.31-1.31)$ & 0.21 & & \\
\hline Surgery in the last year & $10(10.9)$ & $22(10.5)$ & $1.04(0.47-2.30)$ & 0.91 & & \\
\hline Antimicrobial use in the last year & $21(22.8)$ & $57(27.3)$ & $0.79(0.44-1.40)$ & 0.42 & & \\
\hline
\end{tabular}

All values are reported as number (\%) unless otherwise specified. Significant associations are indicated in italic

OR odds ratio, $\mathrm{Cl}$ confidence interval, CNS central nervous system 
Table 2 Uni- and multivariate (logistic regression) analysis of predictors of MRSA carriage in diabetic individuals

\begin{tabular}{|c|c|c|c|c|c|c|}
\hline \multirow[t]{2}{*}{ Factor } & \multirow[t]{2}{*}{ MRSA $(n=15)$} & \multirow[t]{2}{*}{ Negative $(n=287)$} & \multicolumn{2}{|c|}{ Univariate analysis } & \multicolumn{2}{|c|}{$\begin{array}{l}\text { Logistic regression } \\
\text { (multivariate) }\end{array}$} \\
\hline & & & OR $(95 \% \mathrm{Cl})$ & $p$ & OR $(95 \% \mathrm{Cl})$ & $p$ \\
\hline Male gender & $11(73.3)$ & $129(43.3)$ & $3.58(1.11-11.51)$ & 0.02 & $3.64(1.12-11.78)$ & 0.03 \\
\hline Age (median, quartiles) & $58(46-73)$ & $63(54-71)$ & - & 0.27 & & \\
\hline Time since diagnosis, years (median, quartiles) & $13(10-19)$ & $15(9-24)$ & - & 0.56 & & \\
\hline Use of insulin, years (median, quartiles) & $8(3-15)$ & $7(3-12)$ & - & 0.94 & & \\
\hline Diabetes type 2 & $11(73.3)$ & $251(84.5)$ & $0.50(0.15-1.65)$ & 0.27 & & \\
\hline Heart disease & $3(20.0)$ & $74(25.8)$ & $0.72(0.20-2.62)$ & 0.77 & & \\
\hline Lung disease & 0 & $33(11.5)$ & - & 0.39 & & \\
\hline Kidney disease & $4(26.7)$ & $78(27.2)$ & $0.97(0.30-3.15)$ & 1.00 & & \\
\hline Liver disease & $1(6.7)$ & $26(9.1)$ & $0.72(0.09-5.67)$ & 1.00 & & \\
\hline CNS disease & $1(6.7)$ & $49(17.1)$ & $0.35(0.04-2.70)$ & 0.48 & & \\
\hline Cancer & $2(13.3)$ & $37(12.7)$ & $1.06(0.30-4.87)$ & 1.00 & & \\
\hline Trauma & 0 & $31(10.8)$ & - & 0.38 & & \\
\hline Tattoo & $1(6.7)$ & $15(5.2)$ & $1.29(0.16-10.52)$ & 0.57 & & \\
\hline lower-extremity ulcers & $3(20.0)$ & $28(9.8)$ & $2.31(0.61-8.69)$ & 0.19 & & \\
\hline Amputation & $1(6.7)$ & $9(3.1)$ & $2.21(0.26-18.65)$ & 0.40 & & \\
\hline $\begin{array}{l}\text { Charlson comorbidity } \\
\text { index } \geq 1\end{array}$ & $3(2-4)$ & $3(2-4)$ & - & 0.41 & & \\
\hline Hospitalization in the last year & $2(13.3)$ & $46(16.0)$ & $0.81(0.18-3.69)$ & 1.00 & & \\
\hline Surgery in the last year & $3(20.0)$ & $29(10.1)$ & $2.22(0.59-8.34)$ & 0.20 & & \\
\hline Antimicrobial use in the last year & $4(26.7)$ & $74(25.9)$ & $1.04(0.32-3.37)$ & 1.00 & & \\
\hline
\end{tabular}

All values are reported as number (\%) unless otherwise specified. Significant associations are indicated in italic

$O R$ odds ratio, $\mathrm{Cl}$ confidence interval, CNS central nervous system

different individuals and harbored SCCmec type IV. In cluster $\mathrm{B}$, it is possible to observe two isolates carrying SCCmec type I (615 N and 637O) and one isolate carrying SCCmec type IV (72O). The MRSA isolate typed with ApaI is shown in Fig. 2b. None of the isolates grouped with international clones.

Two clusters (A and C) containing four strains and two clusters (B and D) containing strains were obtained for the MSSA isolates (Supplementary Material Figure S1). Cluster A contained two isolates from the nasal and oropharyngeal mucosa of the same subject, demonstrating colonization of different sites with the same isolate. Similarly, in cluster B, two isolates from the nasal and oropharyngeal mucosa of the same subject were grouped with one nasal isolate of another subject. On the other hand, the four isolates of cluster $\mathrm{C}$ were obtained from unrelated individuals and in cluster $\mathrm{D}$ all isolates were from the oral mucosa of different subjects. These findings suggest widespread dissemination of $S$. aureus in the community.

Nine (52.9\%) of the 17 subjects colonized at both sampling sites (nose/oropharynx) carried the same isolate in the nasal and oral mucosa, while eight (47.0\%) carried different $S$. aureus strains in the nose and throat. Interestingly, two of the 17 subjects concomitantly colonized with $S$. aureus in the nose and throat had their strains (nasal and oropharyngeal) typed after digestion with different restriction enzymes. Isolates 6910 and $747 \mathrm{~N}$ were typed with SmaI, while $691 \mathrm{~N}$ and $747 \mathrm{O}$ could only be typed with ApaI, confirming that they are different $S$. aureus strains. There was also one patient colonized with MRSA $(735 \mathrm{~N})$ in the nasal mucosa and with MSSA $(735 \mathrm{O})$ in the oropharyngeal mucosa, both typed with ApaI.

Analysis of typable isolates with ApaI revealed three major clusters (A, C, and D) and three minor clusters of 3 isolates (B, E, and F). In cluster A which contained 14 isolates with $85.6 \%$ similarity, two isolates were from the nasal and oropharyngeal mucosa of the same patient and the remaining from different subjects. The same was observed for clusters C and D. In cluster D, the isolates were grouped with a strain previously identified in another study as ST398 (strain 76 N). These findings are shown in Supplementary Material Figure S2. 


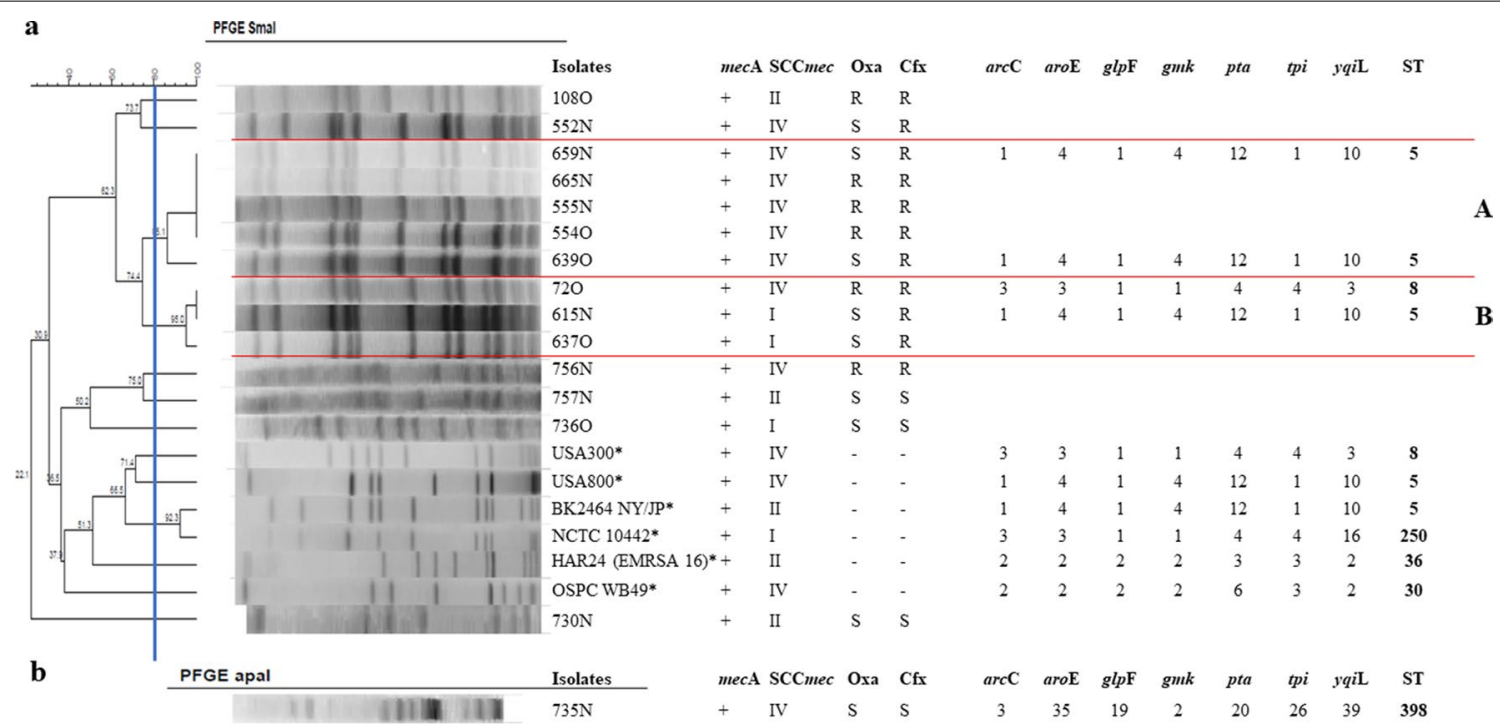

Fig. 2 Dendrogram of the PFGE-Smal and PFGE-Apal profiles of MRSA isolated from insulin-dependent diabetic individuals generated by Dice analysis/UPGMA (BioNumerics, Applied Maths) and their molecular characterization by SCCmec typing and MLST. a. Isolates showing $>80 \%$ similarity (clusters A and B) after digestion with Smal. b. Band pattern of strain $735 \mathrm{~N}$ obtained by digestion with Apal. N, nasal mucosa; O, oropharyngeal mucosa; $\mathrm{S}$, susceptible; $\mathrm{R}$, resistant. * International clones used as controls

\section{Molecular typing of S. aureus and MRSA by multilocus sequence typing (MLST)}

Based on the clusters obtained by PFGE, nine S. aureus isolates (four MSSA and five MRSA) were selected for molecular typing by the MLST technique.

Typing of the MRSA isolates revealed a predominance of sequence type ST5 in three of the four isolates analyzed and one isolate with ST8. Regarding SCCmec type, isolates of the following lineages were obtained: ST5-IV $(\mathrm{n}=2)$, ST5-I $(\mathrm{n}=1)$, and ST8-IV $(\mathrm{n}=1)$. In addition, the strain typed with ApaI by PFGE was characterized as ST398-IV (Fig. 2).

Among the clusters of the MSSA isolates obtained by PFGE that could not be typed with SmaI and that were digested with ApaI, four lineages were selected for MLST. There was a predominance of ST398 $(\mathrm{n}=3)$. However, one isolate exhibited divergence in the allele of the $\operatorname{arcC}$ gene and was sent to the curator of the MLST database (https://pubmlst.org/) for identification of the ST. This isolate was identified as ST 6133 (Fig. 3).

\section{Discussion}

The prevalence of colonization with S. aureus and MRSA among insulin-dependent diabetic individuals was $30.4 \%$ and $4.8 \%$, respectively. Similar data have been reported by Hart et al. [37] who analyzed 258 patients and found a prevalence of $39.1 \%$ for S. aureus and $3.1 \%$ for MRSA among diabetic individuals. In a population-based survey

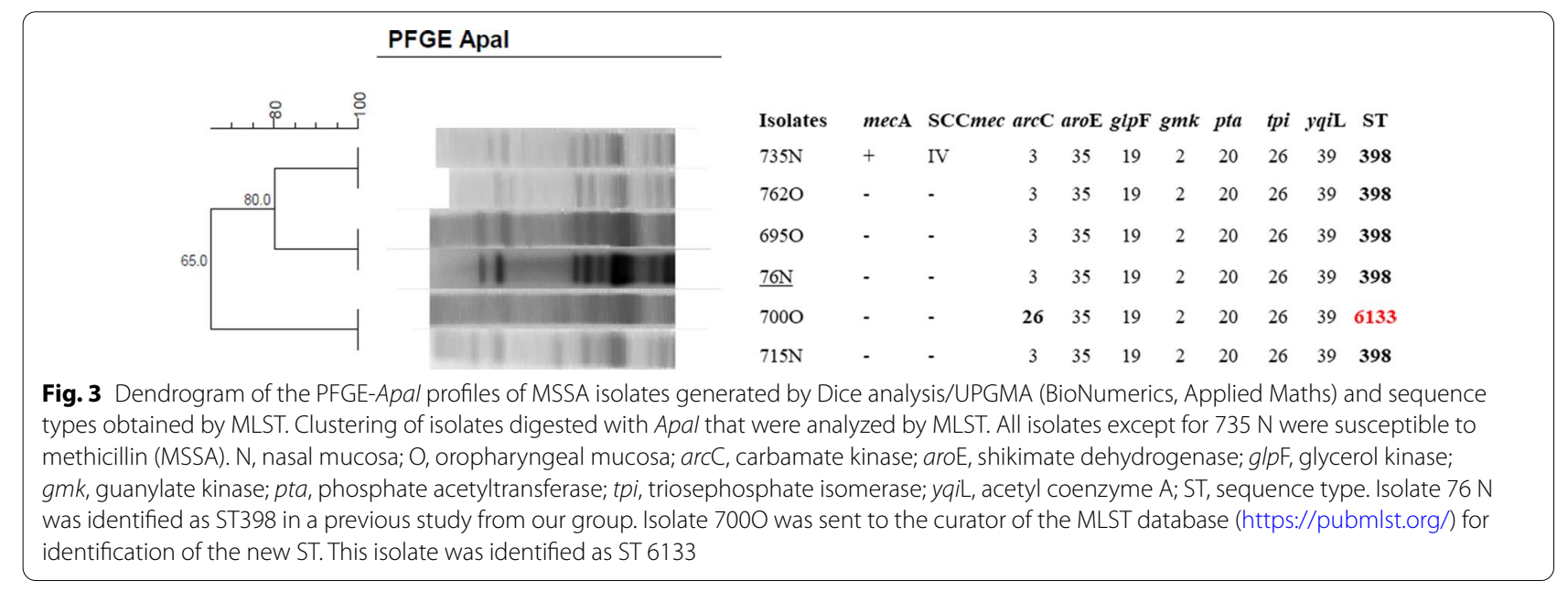


conducted in the same city, Pires et al. [38] found a similar prevalence among community-dwelling individuals, with an overall prevalence of $S$. aureus of $32.7 \%$. However, the prevalence of MRSA was higher in our study $(4.8 \%$ vs $0.9 \%$ ). In a recent study, Lin et al. [2] found a lower prevalence of $S$. aureus and MRSA than that obtained in the present study ( $16.4 \%$ S. aureus and $2.8 \%$ MRSA). The authors suggested that the presence of different microorganisms in the microbiota of these individuals causes competition for the same site, which could explain the variation found in prevalence studies. None of the studies included oral mucosa as a potential site of colonization.

It should be noted that $10.9 \%(\mathrm{n}=34)$ of the subjects were colonized exclusively in the oral mucosa, six of them with MRSA. This finding reinforces the suggestion of Partida et al. [39] that colonization of the oral mucosa can compromise control measures of pathogen dissemination since the throat is not part of routine screening.

The MRSA isolates were identified by phenotypic methods (disc diffusion) and by PCR for detection of the $m e c \mathrm{~A}$ gene. We found four isolates carrying the mecA gene that did not exhibit phenotypic resistance to cefoxitin or oxacillin. Although mecA gene resistance is present in all cells of a population with intrinsic resistance, it may only be expressed by a small proportion of these cells, a fact that results in the so-called heteroresistance [40]. Isolates carrying the $m e c \mathrm{~A}$ gene but that are susceptible to oxacillin/cefoxitin have been reported worldwide and are called oxacillin-susceptible MRSA (OS-MRSA) [4145]. According to Andrade-Figueiredo \& Leal-Balbino [46], this phenomenon may be due to partial excision of SCCmec in multidrug-resistant MRSA isolates or chromosomal integration of the cassette chromosome, resulting in MSSA isolates that contain SCCmec segments.

High antimicrobial resistance of MRSA isolated from diabetic patients has been reported in different studies [14-16]. In our study, there were no multidrug-resistant isolates and none of the isolates was resistant to vancomycin, although one MRSA isolate had a MIC of $1.5 \mu \mathrm{g} /$ $\mathrm{mL}$, indicating a potential therapeutic risk [47-49]. Two other MSSA isolates had a vancomycin MIC of $1.5 \mu \mathrm{g} /$ $\mathrm{mL}$.

In the present study, the analysis of risk factors revealed an association only with lower-extremity ulcers, which is consistent with literature findings showing that the same isolate colonizing the nares was present in foot ulcers and wounds [50,51].

Age was associated with a lower risk of $S$. aureus colonization, with a $2 \%$ decrease in the risk of colonization for each additional year of age. Similar data have been reported by Pereira-Franchi et al. [52]. It is believed that, with increasing age, individuals are exposed to factors (not analyzed in our study) that can prevent colonization with $S$. aureus, in addition to increased ecological competition with other microorganisms.

Lung disease was also a protective factor against the acquisition of $S$. aureus, a fact that might be related to colonization of the respiratory tract with other microorganisms that are competing with $S$. aureus. The nasopharyngeal microbiota changes over time; the level of bacterial colonization is higher during upper respiratory infection [53] and other species such as Streptococcus pneumoniae and Haemophilus influenzae may thus interfere with the capacity of $S$. aureus to persist in the nasal mucosa. Mueller et al. [54] also found a protective effect of age but, in contrast to our findings, lung disease was a risk factor for S. aureus colonization.

Multivariate analysis identified male gender as a risk factor for colonization with MRSA. Similar results were verified in a study of the prevalence of $S$. aureus and MRSA in bedridden individuals and residents of Long-Term Care Institutions for the Elderly (ILPIs) in the same city [55]. In this study developed by Silva [55], the male gender was associated with increased risk for the carrying of $S$. aureus and was also the only variable that showed to be a risk factor for carrying MRSA. Nillius et al. [56] reported that male ILPI residents had an almost double risk for carrying MRSA when compared to women, probably because they had more risk factors than they did.

With respect to clonality of the MRSA isolates, lineages belonging to the most widespread clonal complexes were identified, including CC5-ST5-IV (639O) and CC8-ST8IV (72O) isolated from individuals with colonized oropharyngeal mucosa. This fact reinforces the importance of throat colonization, which could be a route of transmission within the population examined. Other studies involving individuals from the same city and region also found CC5-ST5-IV and CC8-ST8-IV, suggesting that these strains are prevalent in the region [57-62].

Studies suggest a high clonal diversity among $S$. aureus isolates, particularly among MSSA [63]. Among the isolates that could not be typed with SmaI, four were typed by MLST and were characterized as ST398. This fact was also observed by de Souza [61]. The ST398 clonal lineage has been associated with infection and colonization of humans and domestic animals, such as dogs, horses and pigs, in many countries around the world [8]. This lineage is called livestock-associated S. aureus and was described for the first time among both MSSA and MRSA on pig farms in France $[64,65]$. Since then, ST398 has spread rapidly to other animals and has been increasingly related to infections not only in rural workers but also in people and animals without risk factors [31, 66]. Although susceptible to oxacillin, this $S$. aureus lineage is associated with severe infections, as reported by Bonesso et al. 
[67] in patients with ventilator-associated pneumonia in whom the infection was fatal in most cases.

Our finding demonstrated a predominance of SCCmec type IV among isolates, in agreement with the findings of other prevalence studies on non-diabetic individuals conducted in the State of São Paulo [57, 61]. However, SCCmec types I and II were also detected, which are commonly found circulating in health services. This fact has also been reported by Pereira-Franchi et al. [62] and Silveira et al. [68] who found a higher prevalence of isolates harboring SCCmec type II, which was attributed to a history of hospitalization.

It is worth mentioning that patients in hospital-community settings, such as bedridden or institutionalized older adults with chronic infections, have a higher prevalence of SCCmec types I and II [62, 68]; in addition, hospitalized patients frequently carry isolates that harbor SCCmec type III. These SCCmec are larger and carry plasmids and transposons with other resistance genes, often multidrug-resistant genes. On the other hand, community-dwelling patients are associated with SCCmec types IV and V, which are smaller and carry only the $m e c A$ gene of methicillin resistance [38].

One limitation of the present study is the small number of MRSA isolates $(n=15)$, which may result in a low statistical power of the analyses. In addition, the patients studied are not typically community-dwelling since they often need to seek health services (primary care) because of their diabetes.

The present study provides important data about the epidemiology of S. aureus and MRSA in a population of insulin-dependent diabetic individuals. The isolates analyzed had a low rate of resistance to the tested drugs, with only one isolate being resistant to sulfamethoxazole-trimethoprim; however, the prevalence of MRSA was higher than that found in a population-based study conducted in the same city on healthy individuals [38]. Within this context, screening for oral colonization is extremely important since some individuals were colonized only at this body site. In the population studied here, clones were detected among the MSSA and MRSA isolates and an important clonal lineage (ST398) was identified. These data suggest widespread dissemination of MRSA in the population of insulindependent diabetic patients studied, as well as the emergence of important $S$. aureus lineages in these individuals.

\section{Supplementary information}

Supplementary information accompanies this paper at https://doi. org/10.1186/s12941-020-00401-y.

Additional file 1. They were included as tables of the characteristics of the individuals included and excluded from the study. In addition to the dendrograms of the PFGE-Smal and PFGE-Apal profiles of MSSA isolated from insulin-dependent diabetic individuals.
Acknowledgements

This work was funded by the São Paulo State Research Foundation (FAPESPGrant 2017/21396-0 and Grant 2020/15118-0), by the Coordination for Improvement of Higher Education Personnel (CAPES) through a Master/ Doctorate Grant program, and by the National Council for Scientific and Technological Development (CNPq; Grant 304051/2017-9).

\section{Authors' contributions}

NBT and MLRSC designed the study and wrote the manuscript. NBT. and MCS performed the experiments. NBT, TAMP and BPCC collected the samples. CMCBF contributed to the study design and performed the statistical analysis. All authors read and approved the final version of the manuscript.

\section{Availability of data and materials}

The datasets used and analyzed during the current study are available from the corresponding author on reasonable request.

\section{Ethical approval and consent to participate}

The study was approved by the Ethics Committee of the Botucatu Medical School, Brazil (Approval No. 1.107.685). All data were obtained by interview with the patient and/or legal representative following ethical standards, who agreed to participate by signing the consent form.

\section{Consent for publication}

Not applicable.

\section{Competing interests}

The author(s) declare no competing interests.

\section{Author details}

${ }^{1}$ Departamento de Infectologia, Dermatologia, Diagnóstico Por Imagem e Radioterapia, Faculdade de Medicina de Botucatu, UNESP - Universidade Estadual Paulista Júlio de Mesquita Filho, Botucatu, SP, Brasil. ${ }^{2}$ Departamento de Ciências Químicas e Biológicas, Instituto de Biociências de Botucatu, UNESP - Universidade Estadual Paulista Júlio de Mesquita Filho, Botucatu, SP, Brasil. ${ }^{3}$ Departamento de Clínica Médica - Endocrinologia, UNESP - Universidade Estadual Paulista Júlio de Mesquita Filho, Botucatu, SP, Brasil. ${ }^{4}$ Departamento de Ciências Químicas e Biológicas - Setor Microbiologia e Imunologia, Instituto de Biociências de Botucatu (IBB)-Laboratório de Bacteriologia. Rua Plínio Silva, CEP: 18618-970 - Distrito de Rubião Júnior, Botucatu, SP, Brasil.

Received: 27 August 2020 Accepted: 19 November 2020

Published online: 10 February 2021

References

1. WHO guideline: Global report on diabetes. Geneva: WHO; 2016. p. 88

2. Lin SY, Lin NY, Huan YY, Hsieh CC, Huang YC. Methicillin-resistant Staphylococcus aureus nasal carriage and infection among patients with diabetic foot ulcer. J Microbiol Immunol Infect. 2018. https://doi.org/10.1016/j. jmii.2018.03.005.

3. Cho NH, Shaw JE, Karuranga S, Huang Y, da Rocha-Fernandes JD, Ohlrogge AW, et al. Diabetes Atlas: Global estimates of diabetes prevalence for 2017 and projections for 2045. Diab Res Clin Pract. 2018. https://doi. org/10.1016/j.diabres.2018.02.023.

4. Trivedi U, Parameswaran S, Armstrong A, Burgueno-Vega D, Griswold J, Dissanaike $S$, et al. Prevalence of multiple antibiotic resistant infections in diabetic versus nondiabetic wounds. J Pathog. 2014. https://doi. org/10.1155/2014/173053.

5. Enoch S, Williams D, Price P, Harding P. Randomized clinical trial and economic analysis of four-layer compression bandaging for venous ulcers. $\mathrm{Br}$ J of Surg. 2003. https://doi.org/10.1002/bjs.4424.

6. Hewagama S, Spelman T, Woolley M, McLeod J, Gordon D, Einsiedel L. The epidemiology of Staphylococcus aureus and Panton-Valentine Leucocidin (pvl) in Central Australia, 2006-2010. BMC Infect Dis. 2016. https://doi. org/10.1186/s12879-016-1698-5

7. Park SY, Chung DR, Yoo JR, Peck KR, Lee NY, Song JH. Sequence type 72 community-associated methicillin- resistant Staphylococcus aureus emerged as a predominant clone of nasal colonization in newly admitted patients. J Hosp Infect. 2016. https://doi.org/10.1016/j.jhin.2015.12.008. 
8. Camoez M, Sierra JM, Pujol M, Hornero A, Martin R, Dominguez MA. Prevalence and molecular characterization of methicillin-resistant Staphylococcus aureus ST398 resistant to tetracycline at a Spanish hospital over 12 years. PLoS ONE. 2013. https://doi.org/10.1371/journal.pone.0072828.

9. Kalmeijer MD, Coertjens H, van Nieuwland-Bollen PM, Bogaers-Hofman D, Baere GAJ, Stuurman A, et al. Surgical site infections in orthopedic surgery: the effect of mupirocin nasal ointment in a double-blind, randomized, placebo-controlled study. Clin Infect Dis. 2002. https://doi. org/10.1086/341025.

10. von Eiff C, Becker K, Machka K, Stammer H, Peters G. Nasal carriage as a source of Staphylococcus aureus bacteremia. Study group N Engl J Med. 2001. https://doi.org/10.1056/NEJM200101043440102.

11. Stanaway S, Johnson D, Moulik P, Gill G. Methicillin-resistant Staphylococcus aureus (MRSA) isolation from diabetic foot ulcers correlates with nasal MRSA carriage. Diabetes Res Clin Pract. 2007. https://doi.org/10.1016/j. diabres.2006.05.021.

12. Haleem A, Schultz JS, Heilmann KP, Dohrn CL, Diekema DJ, Gardner SE. Concordance of nasal and diabetic foot ulcer staphylococcal colonization. Diagn Microbiol Infect Dis. 2014. https://doi.org/10.1016/j.diagm icrobio.2014.01.014

13. Shah BR, Hux JE. Quantifying the risk of infectious diseases for people with diabetes. Diabetes Care. 2003. https://doi.org/10.2337/diaca re.26.2.510.

14. Onanuga A, Temedie TC. Nasal carriage of multi-drug resistant Staphylococcus aureus in healthy inhabitants of Amassoma in Niger deltaregion of Nigeria. Afr Health Sci. 2011;11:176-81.

15. Kutlu SS, Cevahir NC, Akalin S, Akin F, Caylak SD, Bastemir M, et al. Prevalence and risk factors for methicillin-resistant Staphylococcus aureus colonization in a diabetic outpatient population: a prospective cohort study. Am J Infect Control. 2012. https://doi.org/10.1016/j.ajic.2011.05.009.

16. Alizargar J, Sharif M, Sharif A. Risk factors of methicillin-resistant Staphylococcus aureus colonization in diabetic outpatients. A prospective cohort study. Int J Microbiol Res. 2013. https://doi.org/10.5829/idosi ijmr.2013.4.2.74134

17. Lakhundi S, Zhang K. Methicillin-resistant Staphylococcus aureus: molecular characterization, evolution, and epidemiology. Clin Microbiol Rev. 2018. Doi: https://doi.org/10.1128/CMR.00020-18.

18. Espadinha D, Faria NA, Miragaia M, Lito LM, Melo-Cristino J, de Lencastre $H$, Medicos SN. Extensive dissemination of methicillin-resistant Staphylococcus aureus (MRSA) between the hospital and the community in a country with a high prevalence of nosocomial MRSA. PLOS ONE. 2013. https://doi.org/10.1371/journal.pone.0059960.

19. Melter O, Urbaskova P, Jakubu V, Mackova B, Zemlickova H. Emergence of EMRSA-15 clone in hospitals throughout the Czech Republic. Euro Surveill. 2006. https://doi.org/10.2807/esw.11.31.03017-en.

20. Ma XX, Ito T, Tiensasitorn C, Jamklang M, Chongtrakool P, Boyle-Vavra S, et al. Novel type of staphylococcal cassette chromosome mec identified in community-acquired methicillin-resistant Staphylococcus aureus strains. Antimicrob Agents Chemother. 2002. https://doi.org/10.1128/ aac.46.4.1147-1152.2002.

21. Daskalaki M, Otero JR, Sanz F, Chaves F. Bacteremia due to clonally derived methicillin-resistant, gentamicin-susceptible isolates and methicillin-susceptible, gentamicin-resistant isolates of Staphylococcus aureus. J Clin Microbiol. 2007. https://doi.org/10.1128/JCM.00972-07.

22. Robinson DA, Enright MC. Multilocus sequence typing and the evolution of methicillin-resistant Staphylococcus aureus. Clin Microbiol Infect. 2004 https://doi.org/10.1111/j.1469-0691.2004.00768.x.

23. Herold BC, Immergluck LC, Maranan MC, Lauderdale DS, Gaskin RE, BoyleVavra S, et al. Community-acquired methicillin-resistant Staphylococcus aureus in children with no identified predisposing risk. JAMA. 1998. https ://doi.org/10.1001/jama.279.8.593.

24. Cunha MLRS. Staphylococcus aureus and Coagulase-Negative Staphylococci: Virulence, Antimicrobial Resistance and Molecular Epidemiology. Nova lorque: Nova Science Publishers; 2014. p. 117.

25. Cunha MLRS. Staphylococcus aureus: infections, treatment and risk assessment. 1st ed. New York: Nova Biomedical; 2017. p. 135p.

26. Instituto Brasileiro de Geografia e Estatística. Panorama do município de Botucatu, SP. 2019. https://www.ibge.gov.br/cidades-e-estados/sp/botuc atu.html. Accessed 6 July 2019.
27. Konemann EW, Allen SD, Dowell VR, Sommer HM. Introdução à microbiologia médica. Diagnóstico microbiológico: texto e Atlas colorido. 5th ed. Rio de Janeiro: Medsi; 2001. p. 1465p.

28. Cunha MLRS, Sinzato YK, Silveira LVA. Comparison of methods for the identification of coagulase-negative Staphylococci. Mem Inst Oswaldo Cruz. 2004. https://doi.org/10.1590/s0074-02762004000800012.

29. Mason WJ, Blevins JS, Beenken K, Wibowo N, Ojha N, Smeltzer MS. Multiplex PCR protocol for the diagnosis of staphylococcal infection. J Clin Microbiol. 2001. https://doi.org/10.1128/JCM.39.9.3332-3338.2001.

30. Martineau F, Picard FJ, Roy PH, Ouellette M, Bergeron MG. Speciesspecific and ubiquitous-DNA-based assays for rapid identification of Staphylococcus aureus. J Clin Microbiol. 1998. https://doi.org/10.1128/ JCM.36.3.618-623.1998.

31. Clinical and Laboratory Standards Institute (CLSI). Performance Standards for Antimicrobial Disk Susceptibility Testing; twenty-six informational supplement (M100S). Wayne: CLSI, 2016.

32. Murakami K, Minamide W, Wada K, Nakamura E, Teraoka H, Watanabe S. Identification of methicillin-resistant strains of Staphylococci by polymerase chain reaction. J Clin Microbiol. 1991. https://doi.org/10.1128/ JCM.29.10.2240-2244.1991.

33. Oliveira DC, de Lencastre H. Multiplex PCR strategy for rapid identification of structural types and variants of the mec element in methicillin-resistant Staphylococcus aureus. Antimicrob Agents Chemother. 2002. https://doi. org/10.1128/AAC.46.7.2155-2161.2002.

34. Milheiriço C, Oliveira DC, de Lencastre H. Update to the multiplex PCR strategy for assignment of mec element types in Staphylococcus aureus. Antimicrob Agents Chemother. 2007. https://doi.org/10.1128/AAC.00275 $-07$.

35. McDougal LK, Steward CD, Killgore GE, Chaitram JM, McAllister SK, Tenover FC. Pulsed-field gel electrophoresis typing of oxacillin-resistant Staphylococcus aureus isolates from the United States: establishing a national database. J Clin Microbiol. 2003. https://doi.org/10.1128/ JCM.41.11.5113-5120.2003.

36. Enright MC, Day NP, Davies CE, Peacock SJ, Spratt BG. Multilocus sequence typing for characterization of methicillin-resistant and methicillin-susceptible clones of Staphylococcus aureus. J Clin Microbiol. 2000. https://doi.org/10.1128/JCM.38.3.1008-1015.2000.

37. Hart J, Hamilton EJ, Makepeace A, Davis WA, Latkovic E, Lim EM, et al. Prevalence, risk factors and sequelae of Staphylococcus aureus carriage in diabetes: the Fremantle Diabetes Study Phase II. J Diabetes Complications. 2015. https://doi.org/10.1016/j.jdiacomp.2015.06.005.

38. Pires FV, Cunha MLRS, Abraão LM, Martins PY, Camargo CH, Fortaleza CMCB. Nasal carriage of Staphylococcus aureus in Botucatu, Brazil: a population-based survey. PLoS ONE. 2014. https://doi.org/10.1371/journ al.pone.0092537.

39. Partida AH, Espuñes TS, Martínez JB. Characterization and persistence of Staphylococcus aureus strains isolated from the anterior nares and throats of healthy carriers in a Mexican community. J Clin Microbiol. 2010. https ://doi.org/10.1128/JCM.01929-09.

40. Tomasz A, Nachman S. Stable classes of phenotypic expression in methicillin-resistant clinical isolates of staphylococci. Antimicrob Agents Chemother. 1991. https://doi.org/10.1128/aac.35.1.124.

41. Kampf, G. Adena S, Rüden H, Weist K. Inducibility and potential role of mecA-gene-positive oxacillin-susceptible Staphylococcus aureus from colonized healthcare workers as a source for nosocomial infections. J Hosp Infect. Doi: https://doi.org/10.1016/s0195-6701(03)00119-1.

42. Forbes BA, Bombicino K, Plata K, Cuirolo A, Webber D, Bender CL, et al. Unusual form of oxacillin resistance in methicillin-resistant Staphylococcus aureus clinical strains. Diagn Microbiol Infect Dis. 2008. https://doi. org/10.1016/j.diagmicrobio.2008.04.003.

43. Ikonomidis A, Michail G, Vasdeki A, Labrou M, Karavasilis V, Stathopoulos $C$, et al. In vitro and in vivo evaluations of oxacillin efficiency against mecApositive oxacillin-susceptible Staphylococcus aureus. Antimicrob Agents Chemother. 2008. https://doi.org/10.1128/AAC.00653-08.

44. Saeed K, Dryden M, Parnaby R. Oxacillin-susceptible MRSA, the emerging MRSA clone in the UK? J Hosp Infect. 2010. https://doi.org/10.1016/j. jhin.2010.03.004.

45. Conceição T, Coelho C, de Lencastre H, Aires-de-Sousa M. Frequent occurrence of oxacillin-susceptible mecA-positive Staphylococcus aureus (OS-MRSA) strains in two African countries. J Antimicrob Chemother. 2015. https://doi.org/10.1093/jac/dkv261. 
46. Andrade-Figueiredo M, Leal-Balbino TC. Clonal diversity and epidemiological characteristics of Staphylococcus aureus: high prevalence of oxacillin-susceptible mecA-positive Staphylococcus aureus (OS-MRSA) associated with clinical isolates in Brazil. BMC Microbiol. 2016. https://doi. org/10.1186/s12866-016-0733-4.

47. Soriano A, Marco F, Martínez JA, Pisos E, Almela M, Dimova VP, et al. Influence of vancomycin minimum inhibitory concentration on the treatment of methicillin-resistant Staphylococcus aureus bacteremia. Clin Infect Dis. 2008. https://doi.org/10.1086/524667.

48. Howden BP, Ward PB, Charles PGP, Korman TM, Fuller A, du Cros P, et al. Treatment outcomes for serious infections caused by methicillin-resistant Staphylococcus aureus with reduced vancomycin susceptibility. Clin Infect Dis. 2004. https://doi.org/10.1086/381202.

49. Yeg YC, Yeh KM, Lin TY, Chiu SK, Yang YS, Wang YC, et al. Impact of vancomycin MIC creep on patients with methicillin-resistant Staphylococcus aureus bacteremia. J Microbiol Immunol Infect. 2012. https://doi. org/10.1016/j.jmii.2011.11.006.

50. Richard JL, Sotto A, Lavigne JP. New insights in diabetic foot infection. World J Diabetes. 2011. https://doi.org/10.4239/wjd.v2.i2.24.

51. Taha AB. Relationship and susceptibility profile of Staphylococcus aureus infection diabetic foot ulcers with Staphylococcus aureus nasal carriage. Foot (Edinb). 2013. https://doi.org/10.1016/j.foot.2012.10.003.

52. Pereira-Franchi EPL, Barreira MRN, da Costa NSLM, Fortaleza CMCB, Cunha MLRS. Prevalence of and risk factor associated with the presence of Staphylococcus aureus in the chronic wounds of patients treated in primary health care settings in Brazil. Rev Soc Bras Med Trop. 2017. https ://doi.org/10.1590/0037-8682-0205-2017.

53. Pettigrew MM, Gent JF, Revai K, Patel JA, Chonmaitree T. Microbial interactions during upper respiratory tract infections. Emerg Infect Dis. 2008. https://doi.org/10.3201/eid1410.080119.

54. Muller LMAJ, Gorter KJ, Hak E, Goudzwaard WL, Schellevis FG, Hoepelman IM, et al. Increased risk of common infections in patients with type 1 and type 2 diabetes mellitus. Clin Infect Dis. 2005. https://doi. org/10.1086/431587.

55. Silva LP. Epidemiologia Molecular de Staphylococcus aureus em pacientes acamados em domicílio ou vivendo em Instituições de Longa Permanência para Idosos no Município De Botucatu, SP. Dissertação (Mestrado). Programa De Pós-Graduação em Biologia Geral e Aplicada, 2019.

56. Nillius D, von Müller L, Wagenpfeil S, Klein R, Herrmann M. MethicillinResistant Staphylococcus aureus in Saarland, Germany: The Long-Term Care Facility Study. PLoS ONE. 2016. https://doi.org/10.1371/journ al.pone. 0153030 .

57. Silveira M. Prevalência e fatores de risco para carreamento de Staphylococcus aureus resistente à meticilina em idosos institucionalizados na cidade de Bauru-SP. Dissertação (Mestrado). Programa de Pós-Graduação em Doenças Tropicais, 2013.

58. Witzel CL, Fortaleza CM, de Souza CS, Riboli DF, Cunha MLRS. Nasopharyngeal carriage of Staphylococcus aureus among imprisoned males from Brazil without exposure to healthcare: risk factors and molecular characterization. Ann Clin Microbiol Antimicrob. 2014. https://doi. org/10.1186/1476-0711-13-25.

59. Lastoria LC. Colonização por Staphylococcus aureus em pessoas vivendo com HIV/AIDS acompanhadas em um serviço ambulatorial de referência em Botucatu (SP): prevalência, resistência à meticilina e epidemiologia molecular. Dissertação (Mestrado). Programa de Pós-Graduação em Doenças Tropicais, 2016.

60. Abraão LM. Carreamento nasal/oral de Staphylococcus aureus em populações indígenas do norte e sudeste do brasil: resistência antimicrobiana, virulência, fatores de risco e epidemiologia molecular. Tese (Doutorado). Programa de Pós-Graduação em Doenças Tropicais, 2017.

61. de Souza CSM. Determinação da relação clonal e virulência de Staphylococcus aureus isolados de pacientes vivendo com HIV/AIDS e seus familiares. Tese (Doutorado). Programa de Pós-Graduação em Doenças Tropicais, 2018.

62. Pereira-Franchi EPL, Barreira MRN, da Costa NSLM, Riboli DFM, Abraão LM, Martins KB, et al. Molecular epidemiology of MRSA in the Brazilian primary health care system. Trop Med Int Health. 2018. https://doi. org/10.1111/tmi.13192.

63. Robinson DA, Enright MC. Evolutionary models of the emergence of methicillin-resistant Staphylococcus aureus. Antimicrob Agents Chemother. 2003. https://doi.org/10.1128/AAC.47.12.3926-3934.2003.

64. Bens CCPM, Voss A, Klaassen CHW. Presence of a novel DNA methylation enzyme in methicillin-resistant Staphylococcus aureus isolates associated with pig farming leads to uninterpretable results in standard pulsedfield gel electrophoresis analysis. J Clin Microbiol. 2006. https://doi. org/10.1128/JCM.44.5.1875-1876.2006.

65. Witte W, Strommenger B, Stanek C, Cuny C. Methicillin-resistant Staphylococcus aureus ST398 in humans and animals. Central Europe Emerg Infect Dis. 2007. https://doi.org/10.3201/eid1302.060924.

66. Chung M, de Lencastre H, Matthews P, Tomasz A, Adamsson I, Aires-deSouza M, et al. Molecular typing of methicillin-resistant Staphylococcus aureus by pulsed-field gel electrophoresis: comparison of results obtained in a multilaboratory effort using identical protocols and MRSA strains. Microb Drug Resist. 2000. https://doi.org/10.1089/mdr.2000.6.189.

67. Bonesso MF, Yeh AJ, Villaruz AE, Joo HS, McCauslan J, Fortaleza CMCB, et al. Key role of a-toxin in fatal pneumonia caused by sequence type 398. Am J Respir Crit Care Med. 2016. https://doi.org/10.1164/rccm.20150 6-1225LE.

68. Silveira M, da Cunha MLRS, de Souza CSM, Correa AAF, Fortaleza CMCB. Nasal colonization with methicillin resistant Staphylococcus aureus among elderly living in nursing homes in Brazil: risk factors and molecular epidemiology. Ann Clin Microbiol Antimicrob. 2018. https://doi.org/10.1186/ s12941-018-0271-z.

\section{Publisher's Note}

Springer Nature remains neutral with regard to jurisdictional claims in published maps and institutional affiliations. 